University of Nebraska - Lincoln

DigitalCommons@University of Nebraska - Lincoln

Nebraska Cooperative Fish \& Wildlife Research Nebraska Cooperative Fish \& Wildlife Research Unit -- Staff Publications

2017

\title{
Species Distributions Models in Wildlife Planning: Agricultural Policy and Wildlife Management in the Great Plains
}

\author{
Joseph J. Fontaine \\ University of Nebraska-Lincoln, jfontaine2@unl.edu \\ Christopher F. Jorgensen \\ Olsson Associates \\ Erica F. Stuber \\ Nebraska Cooperative Fish and Wildlife Research Unit, efstuber@gmail.com \\ Lutz F. Gruber \\ Nebraska Cooperative Fish and Wildlife Research Unit \\ Andrew A. Bishop \\ U.S. Fish and Wildlife Service
}

\begin{abstract}
Bellowexhisagredfaddidititiaha/cakthot.shttps://digitalcommons.unl.edu/ncfwrustaff
Part of the Aquaculture and Fisheries Commons, Environmental Indicators and Impact Assessment Commons, Environmental Monitoring Commons, Natural Resource Economics Commons, Natural Resources and Conservation Commons, and the Water Resource Management Commons
\end{abstract}

Fontaine, Joseph J.; Jorgensen, Christopher F.; Stuber, Erica F.; Gruber, Lutz F.; Bishop, Andrew A.; Lusk, Jeffrey J.; Zach, Eric S.; and Decker, Karie L., "Species Distributions Models in Wildlife Planning: Agricultural Policy and Wildlife Management in the Great Plains" (2017). Nebraska Cooperative Fish \& Wildlife Research Unit -- Staff Publications. 234.

https://digitalcommons.unl.edu/ncfwrustaff/234

This Article is brought to you for free and open access by the Nebraska Cooperative Fish \& Wildlife Research Unit at DigitalCommons@University of Nebraska - Lincoln. It has been accepted for inclusion in Nebraska Cooperative Fish \& Wildlife Research Unit -- Staff Publications by an authorized administrator of DigitalCommons@University of Nebraska - Lincoln. 


\section{Authors}

Joseph J. Fontaine, Christopher F. Jorgensen, Erica F. Stuber, Lutz F. Gruber, Andrew A. Bishop, Jeffrey J. Lusk, Eric S. Zach, and Karie L. Decker 
Original Article

\title{
Species Distributions Models in Wildlife Planning: Agricultural Policy and Wildlife Management in the Great Plains
}

\author{
JOSEPH J. FONTAINE, ${ }^{1}$ U.S. Geological Survey, Nebraska Cooperative Fish and Wildlife Research Unit, School of Natural Resources, University of \\ Nebraska-Lincoln, Lincoln, NE 68583, USA \\ CHRISTOPHER F. JORGENSEN, Olsson Associates, Lincoln, NE 68508, USA \\ ERICA F. STUBER, Nebraska Cooperative Fish and Wildlife Research Unit, School of Natural Resources, University of Nebraska-Lincoln, Lincoln, \\ NE 68583, USA \\ LUTZ F. GRUBER, Nebraska Cooperative Fish and Wildlife Research Unit, School of Natural Resources, University of Nebraska-Lincoln, Lincoln, \\ NE 68583, USA
}

ANDREW A. BISHOP, U.S. Fish and Wildife Service, Rainwater Basin Joint Venture, Grand Island, NE 68801, USA

JEFFREY J. LUSK, Nebraska Game and Parks Commission, Lincoln, NE 68503, USA

ERIC S. ZACH, Nebraska Game and Parks Commission, Lincoln, NE 68503, USA

KARIE L. DECKER, Nebraska Game and Parks Commission, Lincoln, NE 68503, USA

\begin{abstract}
We know economic and social policy has implications for ecosystems at large, but the consequences for a given geographic area or specific wildlife population are more difficult to conceptualize and communicate. Species distribution models, which extrapolate species-habitat relationships across ecological scales, are capable of predicting population changes in distribution and abundance in response to management and policy, and thus, are an ideal means for facilitating proactive management within a larger policy framework. To illustrate the capabilities of species distribution modeling in scenario planning for wildlife populations, we projected an existing distribution model for ring-necked pheasants (Phasianus colcbicus) onto a series of alternative future landscape scenarios for Nebraska, USA. Based on our scenarios, we qualitatively and quantitatively estimated the effects of agricultural policy decisions on pheasant populations across Nebraska, in specific management regions, and at wildlife management areas. Published 2017. This article is a U.S. Government work and is in the public domain in the USA.
\end{abstract}

KEY WORDS agricultural policy, hierarchical mixture model, Phasianus colchicus, ring-necked pheasant, scenario planning, species distribution model.

Conservation efforts that emphasize improving habitat quality clearly influence management outcomes (Wiens 1973, Patterson and Best 1996, Helzer and Jelinski 1999, Fisher and Davis 2010), but ecological factors acting outside the management unit are increasingly identified as inhibiting management success (Fletcher and Koford 2002, Cunningham and Johnson 2006, Jorgensen et al. 2014, Simonsen and Fontaine 2016). Unfortunately, despite considerable interest in incorporating policy constraints into wildlife management planning, there are surprisingly few successful examples (Margules and Pressey 2000, Groves 2003, Halpern et al. 2006). The challenge lies in the inherent separation between the scales at which natural resource management and natural resource policy affect socio-ecological systems (Cumming

Received: 28 June 2016; Accepted: 23 February 2017

Published: 9 June 2017

${ }^{1}$ E-mail: jfontaine2@unl.edu et al. 2015). Given the limited resources afforded wildlife management, managing wildlife without considering policy constraints likely has economic, social, and political costs. Affected by policy decisions beyond their control, what options are available to wildlife managers when management approaches fail? Is there a means to improve management success by accounting for the constraints imposed by policy decisions?

A species distribution model (SDM) is an analytical tool that extrapolates species-habitat relationships into spatially explicit predictions of population distribution and abundance (Guisan and Zimmermann 2000, Merow et al. 2014). By associating habitat variables with species occurrence or abundance at specific spatial scales, SDMs provide insight into what constitutes habitat (Rosenzweig 1991). More importantly, because SDMs can incorporate habitat attributes across a range of ecological scales, they are sensitive to independent changes in small- and large-scale landscape conditions (Luoto et al. 2007, Shirley et al. 2013). Thus, 
conceptually SDMs are an ideal tool for facilitating proactive management within a larger policy framework, or for identifying and simplifying the effects of policy on a particular species, population, or geographic region. Despite their potential benefits, SDMs lack widespread application by wildlife managers and natural resource policy makers (Guisan et al. 2013). Some resistance to the application of SDMs stems from legitimate concerns about their development (e.g., sampling method, model selection, spatial scale, assumptions; Guisan and Thuiller 2005, Guisan et al. 2007, Elith and Leathwick 2009, Franklin 2010) and use (e.g., correlative vs. causal ecological relationships, robust extrapolation, time lags; Anderson et al. 2002, Nielsen et al. 2005, Austin 2007). Although imperfect, SDMs provide a way to create a working depiction of ecological conditions and corresponding species distributions, and can help managers understand the potential implications of policy decisions on management outcomes.

As a major driver of land-use change, agricultural policy has obvious implications for the success of wildlife conservation at large (Tilman et al. 2001, Mattison and Norris 2005, Giudice and Haroldson 2007, Gottschalk et al. 2007), but the consequences for wildlife management in a given location, or for a specific species are more nebulous (Gottschalk et al. 2007). In the United States, for example, agricultural policy favoring increased production of cornbased ethanol is affecting wildlife populations, but the ubiquity and intensity of its effects are region and species specific (Fargione et al. 2010, Fletcher et al. 2010, Robertson et al. 2012). Similarly, the Conservation Reserve Program (CRP) creates habitat for grassland-obligate species (Buskirk and Willi 2004, Nielson et al. 2008, Herkert 2009), but the relative benefits of CRP vary widely and increasingly are seen as context dependent (McCoy et al. 1999, Rodgers 1999, Rahmig et al. 2008, Jorgensen et al. 2014, Simonsen and Fontaine 2016). Because wildlife managers are primarily concerned with reaching goals for specific wildlife populations, or specific management areas, there is a need to advance approaches that downscale agricultural policy to geographic and temporal scales encapsulated by management actions. By incorporating SDMs that account for regional ecological processes, wildlife managers can identify how agricultural policy decisions affect management outcomes and subsequently identify priority landscapes for conservation and management directives (Guisan et al. 2013).

Ultimately, the use of SDMs may help elucidate cross-scale ecological interactions inherent in managing wildlife populations, particularly in highly altered agricultural landscapes. Management success requires knowledge of how policy decisions affect current management possibilities as well as how future conditions may facilitate or constrain long-term goals. Given the complexity of agricultural policy, predicting future landscape conditions is challenging. Scenario planning is an effective means of providing knowledge about systems when action is necessary, but uncertainty about future conditions is high and controllability is limited (Allen et al. 2011). Although we may consider policy decisions within the purview of controllable forces, from the perspective of wildlife managers this is generally not the case (Peterson et al. 2003). Instead, policy represents an externality that affects management implementation but is generally uncontrollable. Scenario planning is an ideal approach for identifying the effects of alternative policy decisions on management outcomes. Moreover, by incorporating policy scenarios into spatially explicit SDMs, managers can better understand not only the effect of policy decisions on wildlife communities but also where decisions will manifest.

To illustrate how managers can use SDMs in scenario planning to proactively facilitate wildlife management efforts, and demonstrate how policy decisions affect wildlife populations, we developed a suite of scenarios that represent potential shifts in agricultural policy in the United States and thus land cover. We modified an existing SDM developed by Jorgensen et al. (2014) to elucidate how changes in land cover resulting from future agricultural policy may affect populations of an important game species, the ring-necked pheasant (Phasianus colchicus). In doing so, we attempted to demonstrate to managers how to work within the constraints of policy decisions to proactively direct management efforts where the likelihood of success is greatest.

\section{METHODS}

\section{Species Distribution Model}

Successfully introduced to North America in the late 1800s, ring-necked pheasants thrived in the diverse croplands of the midwestern United States, but populations have declined since the 1940s (Dahlgren 1988, Giudice and Ratti 2001). Despite a clear understanding of habitat requirements, efforts to reverse population declines of ring-necked pheasants through habitat management often failed to meet population goals, likely due to constraints imposed by agricultural policy decisions (Leif 1994, Robertson 1996, Rodgers 1999). In Nebraska, USA, for example, agricultural policy that favors reductions in CRP enrollment, and increased intensification of agricultural practices has largely hampered attempts to increase ring-necked pheasant populations through habitat enhancement (e.g., Nebraska Game and Parks Commission's Focus on Pheasants program, Pheasants Forever's Reload Nebraska program). Given the social and economic value of pheasants and pheasant hunting to communities across the United States, there is a need to develop approaches that can inform managers about how agricultural policy influences pheasant populations, and thus, how to best direct management actions given larger policy decisions (Hansen et al. 1999, Sullivan et al. 2004).

We used a species distribution model previously developed to quantify ring-necked pheasant abundance and habitat relationships in Nebraska based on aural survey data collected across 17 counties in Nebraska, from April-July of 2010-2012 (see Jorgensen et al. 2014 for model details). Jorgensen et al. (2014) derived landscape variables from a $30 \times 30-\mathrm{m}$ resolution land cover layer and generalized land cover types (CRP, all non-CRP grass, trees, small grains, corn and soybean row 
crops, and wetlands) to classify landscapes (Bishop et al. 2011). The relative abundance of ring-necked pheasants at each survey site was modeled using a binomial-Poisson hierarchical mixture model that accounted for imperfect detection and spatial autocorrelation. Jorgensen et al. (2014) created independent models that considered the effect of land cover on pheasant abundance at 2 spatial scales, a management (314ha) and landscape scale (7,854ha). Developing 2 independent models allowed for interpretation of the scale at which each land cover type influenced abundance. The spatial scale at which each land cover type had a stronger relationship with abundance was included in the final mixedscale model. The final model employed a Bayesian binomialPoisson hierarchical structure to describe relative abundance of ring-necked pheasants at each survey site while accounting for the distribution of pheasants on the landscape and the observers' probability of detecting individuals during a survey (full model description detailed in Jorgensen et al. 2014). Using parameter estimates of the pheasant habitat relationships derived from the final model for each of the major land cover categories in Jorgensen et al. (2014), we projected the relative pheasant abundance under various future land cover scenarios across Nebraska.

\section{Agricultural Policy Scenarios and Alternative Distribution Models}

Although simple in concept, the challenge of effective scenario development is the identification of plausible alternative states and their subsequent implications (Peterson et al. 2003). Scenarios are not prescriptions but informative tools to help shape the decision process and identify alternatives (Peterson et al. 2003, Nassauer and Corry 2004). The most effective means to develop a suite of possible management solutions is to work with stakeholders with a vested interest in the issue at hand to develop scenario portfolios that encompass a continuum of futures from the highly probable to the reasonable but unexpected (Schwartz 1991, Beck et al. 2002). In regards to wildlife management questions, stakeholder groups often include state and federal wildlife agencies, non-government environmental organizations, private citizens, and landowners. Although traditional wildlife stakeholder groups can be effective in developing alternatives, including non-wildlife related agencies, industry, or even political organizations can allow for a larger, more encompassing perspective and ultimately more support for the process.

Though narrowly referencing agricultural directives (e.g., U.S. 2002 Farm Security and Rural Investment Act), agricultural policy includes the suite of policy decisions that affect the social, economic, and technological aspects of agricultural production (Mattison and Norris 2005). Clearly, directed subsidies, crop insurance, and conservation initiatives shape agricultural landscapes, but so do more broadbased economic, energy, and foreign affairs policies (Wu 1999, Mattison and Norris 2005, Gottschalk et al. 2007, Polyakov and Zhang 2008, Herkert 2009). Thus, with respect to agricultural policy, development of scenario portfolios must not only consider trends in land-use practices (e.g., expansion of corn) but also technological advances (e.g., low-water corn), economic shifts (e.g., trade relationships), or even how policy decisions direct the geographic distribution of land-use practices on the landscape.

We considered a range of agricultural policy scenarios that encompassed reasonable expectations based on current land-use trajectories through 2025, and the possibility of the establishment of novel policies (Fig. 1; U.S. Department of Agriculture [USDA] 2014). We chose a 10-year timeline for projecting land-use change because it is a common timeline for wildlife management plans (e.g., State Wildlife Action Plans), but it is possible to incorporate any time projection into scenario planning. If, for example, we intended to model climate change effects, a longer timeline would be necessary. We selected a shorter timeline because our primary interest was in modeling the effects of land-use change, which in Nebraska can happen rapidly. For example, the land area dedicated to corn production in Nebraska increased drastically following the enactment of the Energy Independence and Security Act [EISA] of 2007 (Fig. 1), which included provisions for increasing the production and use of biofuels (U.S. EISA 2007). We focused our modeling efforts on changes in land cover most influential in shaping pheasant distribution: corn, small grains (wheat and sorghum), and CRP (Taylor et al. 1978, Best et al. 1995, Jorgensen et al. 2014). In doing so, we made the following assumptions.

1. Land available for cultivation will not increase beyond the long-term historical average, roughly 8.8 million ha (Hiller et al. 2009). Although, recent trends suggest increases in arable land, this is likely due to the conversion of CRP back into crops rather than the conversion of lands (e.g., grasslands) not previously in row-crop agriculture (Fig. 2). Although it is possible that genetic advances, or extreme upward pressure on commodity prices will favor arable land expansion, this seems unlikely because Nebraska has exceeded 9.5 million ha of cropland only twice in 150 years (Hiller et al. 2009).

2. Corn will remain the preferred agricultural commodity in Nebraska. Agricultural diversity in Nebraska peaked in the early 1960s and since that time, the proportion of the landscape in a corn or corn-soybean rotation has continued to increase (Hiller et al. 2009). With the development of ethanol refinery capacity in Nebraska, this trend is unlikely to change.

3. Land conversion is predicated on the greatest economic return (Bell et al. 2006) as indicated by the dominant agricultural practice in the surrounding landscape. Although it is difficult to predict future land use for any individual parcel, by assuming the surrounding agricultural practices predict the environmental suitability (e.g., soil, precipitation), production capability, and thus economic value of the land (Rashford et al. 2011), we can weight the likelihood of conversion from one land-use practice to another. Under this assumption, parcels are more likely to convert to a given land-use practice if the practice is already common in the surrounding landscape. 


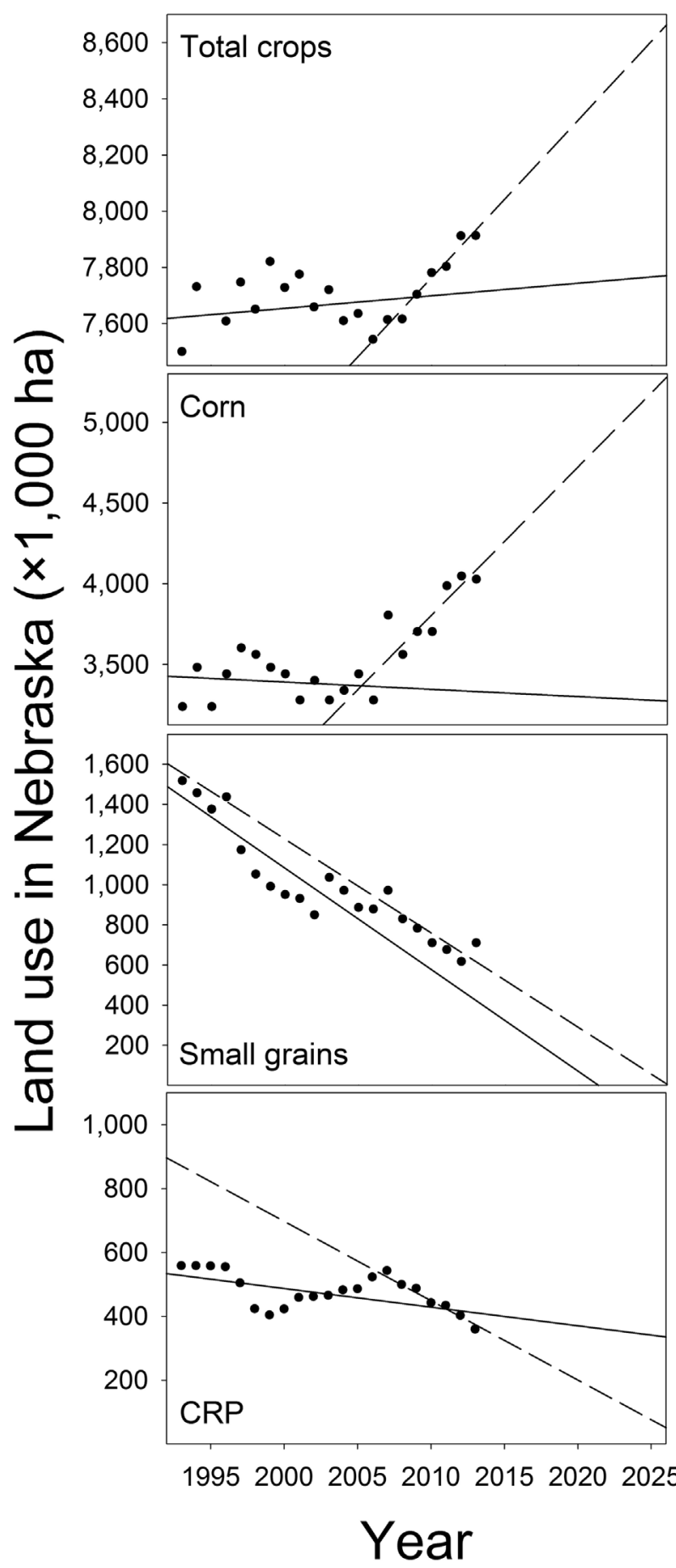

Figure 1. Current and projected future land use for Nebraska, USA, extrapolated from linear regression lines of 4 land-use practices (total crop, corn, small grain, and Conservation Reserve Program [CRP]) from 1993-2007 (solid line) to 2007-2013 (dashed line), based on county-level agricultural statistics (U.S. Department of Agriculture 2014). The choice of periods reflects the change in policy and subsequent land-use practices associated with the Energy Independence and Security Act of 2007.

4. The dominant climate conditions in Nebraska will persist throughout the scenario projection (2025). Climate change can clearly affect species distribution (Chen et al. 2011) and agricultural practices (Walthall et al. 2012), so incorporating climate change into scenario planning can improve predicted species-habitat relationships in agroecosystems. However, we must weigh the benefit of adding scenarios (e.g., future climate conditions) against the cost of increasing complexity and ability to address the question at hand (Peterson et al. 2003). Given that even extreme climate models (Smith et al. 2015) predict conditions in the next decade that fall within the variation in climatic conditions over the last century in Nebraska (Shulski et al. 2013), we assumed that climate, and the biophysical processes it affects, remain as they are currently.

Incorporating our basic assumptions, we created 5 scenarios: static, minimal CRP, spatially directed CRP, corn trend, and small grain reinvigoration.

1. Static-The baseline model, which used land-cover conditions (circa 2010) at the time of the statewide pheasant survey (Jorgensen et al. 2014) and associated ring-necked pheasant habitat relationships to predict pheasant distribution. Assuming land cover remains constant, this model would represent the predicted relative abundance for pheasants in Nebraska in 2025.

2. Minimal CRP-Our second scenario assumed a reduction in CRP coverage from the static model by roughly $50 \%$ to $182,500 \mathrm{ha}$, resulting in a $4.6 \%$ increase in total corn coverage. Although the recent rate of CRP conversion would indicate the near loss of CRP before 2025 (Fig. 1), this is unlikely given the importance placed on CRP by the conservation community. However, the combined pressures of increased commodity prices and decreased support for federal spending also makes it unreasonable to expect CRP enrollment to be maintained at historical highs (Stubbs 2014). Given the uncertainty in future CRP enrollment, a reasonable expectation is likely somewhere in between the 2 trend lines (Fig. 1). Reductions in CRP enrollment will likely be proportionate to the economic value of the replacement agricultural commodity (Secchi et al. 2009). In Nebraska, this means that the majority of CRP conversion will occur in the eastern half of the state, where conversion to corn offers the greatest economic incentive (Wilhelmi and Wilhite 2002). To account for both the loss and the change in distribution of CRP, we weighted the probability that any one parcel of CRP would convert to a corn cover-type based on the proportion of corn in the surrounding $5-\mathrm{km}$ landscape (i.e., conversion was more likely in corndominated landscapes).

3. Spatially directed CRP-The third scenario assumed the loss of CRP would follow current trends (50\% reduction), but that changes in agricultural policy would incorporate ecological conditions acting at the landscape level $(5-\mathrm{km}$ radius) in determining placement of future CRP (USDA 2013). For ring-necked pheasants, CRP lands within $5 \mathrm{~km}$ of grasslands or small grains have significantly more value than lands in a matrix of corn (Jorgensen et al. 2014). Given our increasing understanding of landscape constraints on management success, incorporation of 


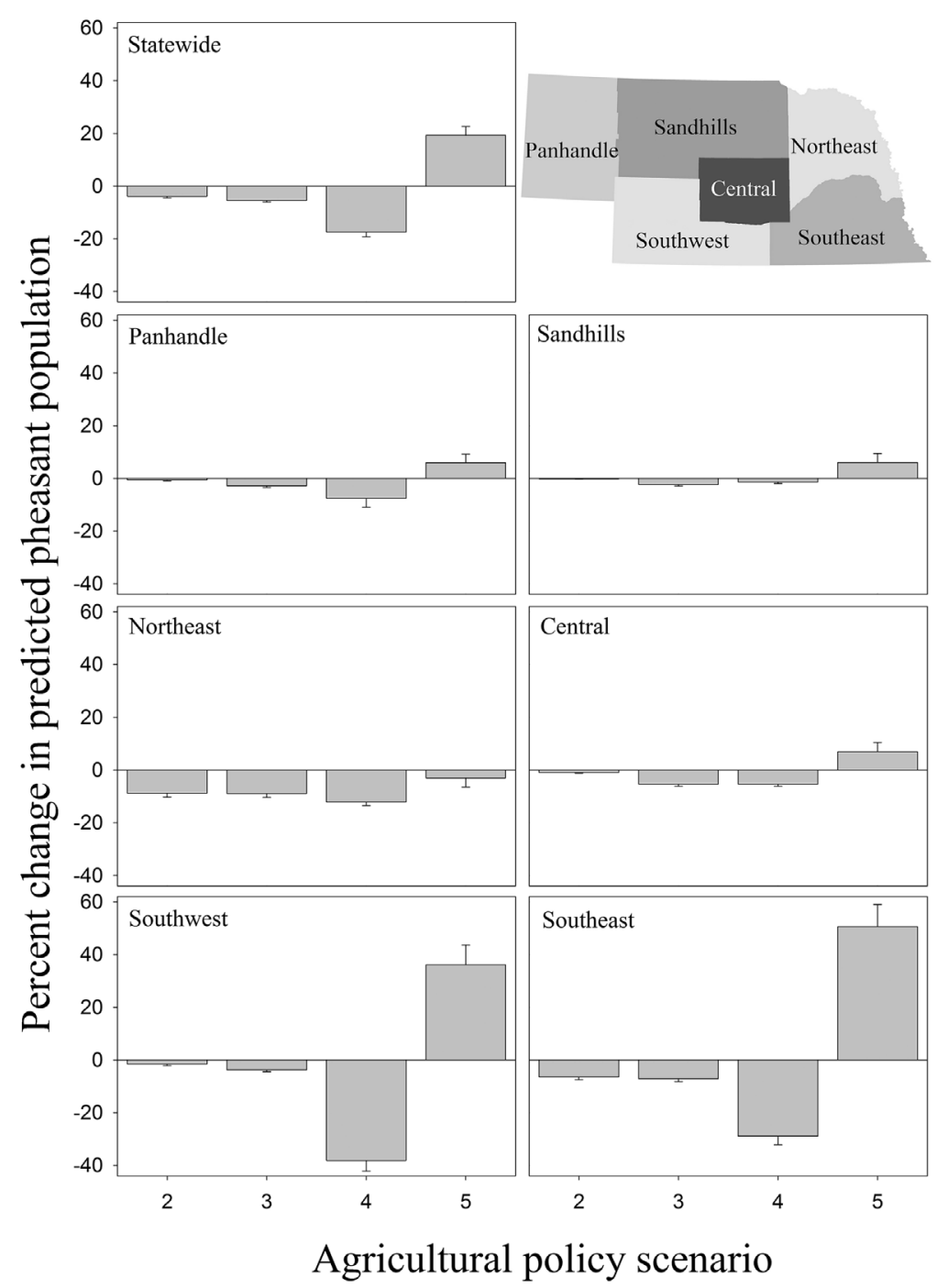

Figure 2. The predicted difference in ring-necked pheasant relative abundance between the static land-use change scenario and 4 alternative agricultural policy scenarios. Columns represent the mean change $( \pm \mathrm{SE})$ in predicted relative abundance of male ring-necked pheasant from April to July for each alternative scenario $(2=$ minimal Conservation Reserve Program [CRP], $3=$ directed CRP, $4=$ corn trend, $5=$ small grain reinvigoration) from the static scenario at the county level: (scenario/current) $-1 \times 100$ (i.e., the horizontal line at zero represents the average relative abundance of ring-necked pheasants based on the static scenario) based on a multi-scale habitat model developed from aural survey data collected in Nebraska, USA, from 2010 to 2012 (Jorgensen et al. 2014). We delineated regions based on historical management units for upland game birds overseen by the Nebraska Game and Parks Commission.

spatially explicit details such as proximity to other wildlife-valued lands may be desirable. To demonstrate this approach, we took the current distribution of CRP in the landscape and randomly reduced it by $75 \%$ to 91,250 ha. We then enrolled 91,250 ha of new CRP to reach the conditions we predict for 2025, or a reduction of roughly 50\% from current levels. In adding CRP to the landscape, we negatively weighted the likelihood that a parcel would convert to CRP by the proportion of corn in the surrounding $5 \mathrm{~km}$, and positively weighted it by the proportion of small grains, grasslands, or CRP within $5 \mathrm{~km}$.

4. Corn trend-This scenario assumed that socioeconomic, political, and technological developments will continue to favor corn production over other agricultural practices, resulting in an additional 550,000 ha, or roughly a $13 \%$ increase in corn in Nebraska compared with the static scenario (Fig. 1). Assuming only 182,500 ha of CRP are available for conversion to corn (see minimal CRP scenario), we also converted 367,500 ha, or roughly, $58 \%$ of the land cover currently in small grains, leaving 265,800 ha of small grains. Again, conversion is unlikely to occur randomly; thus, we weighted the likelihood of small grains converting to corn based on the surrounding agricultural practices as we did for CRP conversion.

5. Small grain reinvigoration-Our final scenario assumed the advent of a new policy that favors increasing small grain production to historical levels, which in the 1960s and 1970 s was 1.9 million ha, or roughly a $200 \%$ increase from current levels (Hiller et al. 2009). Increasing drought frequency (Wetherald and Manabe 1995) and reduced capacity for irrigation in some regions of Nebraska (e.g., Republican River Watershed; Szilagyi 1999), coupled with advancements in biofuel feedstock from small grains 
such as sorghum (Rooney et al. 2007), may favor increased small grain production. Assuming that only 182,500 ha of $\mathrm{CRP}$ are available for conversion (see minimal CRP scenario), to reach our goal we converted 1 million ha of corn to small grain. This required roughly $25 \%$ of the land cover currently in corn to be transitioned to small grains, resulting in 3 million ha of corn remaining, which we distributed spatially by weighting conversions according to the surrounding agricultural practices, as we did with previous scenarios.

We used each scenario to generate future, prospective land cover classification maps for Nebraska using reclassified land cover designations (Bishop et al. 2011). We then used the previously developed ring-necked pheasant SDM for Nebraska that described observed data (Bayesian $P=0.57$; see Gelman et al. 2004, Gelman and Hill 2007, Jorgensen et al. 2014) and performed well on an independent testing dataset (Jorgensen et al. 2014) to generate pheasant habitat maps based on the predicted relative abundance of pheasants for each scenario. Specifically, we used the inverse of the log link function to back-transform relationships between each land cover type (row crops, CRP, small grain, grass, trees, wetland) and then predicted relative abundance of ringnecked pheasants from the original SDM onto the reclassified land cover from each scenario (Jorgensen et al. 2014).

\section{Statistical Analysis}

The SDMs developed by back-transforming the ring-necked pheasant habitat relationship of each land cover category onto the reclassified land covers resulted in 5 future scenarios that we present in the form of maps depicting the predicted relative abundance of breeding male pheasants across Nebraska. Using Gage County in southeast Nebraska as an example, we also highlight how each scenario may influence pheasant populations on Wildlife Management Areas (WMA) managed by the Nebraska Game and Parks Commission. Although visual depictions are informative, because each pixel represents an estimate, it is also possible to assess more quantitatively the change in predicted pheasant abundance. Using the relative abundance scores for each pixel, we created a mean ring-necked pheasant abundance score for every county in Nebraska under each scenario. To consider how agricultural policy decisions affect management actions, we considered changes in the relative abundance of ring-necked pheasants for the state, and 6 regions (Panhandle, Sandhills, Northeast, Central, Southwest, and Southeast; Fig. 2). Each region represents a historical management district where the Nebraska Game and Parks Commission conducts upland game bird monitoring and management and includes 8-21 counties. We tested whether agricultural policy affected ring-necked pheasant populations by comparing the mean relative abundance of pheasants at the county level (log-transformed to approximate normality) across Nebraska and within each region using a general linear model that included scenario only for the statewide model and scenario and region for the regional model. We used least significant difference $(\alpha=0.05)$ post hoc analysis corrected for multiple tests to compare among the effects of different scenarios and regions, and used the static scenario as our null model to base comparisons.

\section{RESULTS}

Management regions differed in the predicted abundance of breeding male ring-necked pheasants, and type of agricultural policy scenario imposed on the landscape affected pheasant populations in Nebraska (Figs. 2 and 3; scenario: $F_{4,465}=5.95, P<0.001$; region: $F_{5,465}=85.79, P<0.001$; scenario $\times$ region: $\left.F_{5,465}=1.44, P=0.10\right)$. A $50 \%$ reduction in CRP from current levels reduced ring-necked pheasant populations across Nebraska (minimal CRP: $-3.8 \% \pm 0.55$ [SE]; spatially directed CRP: $-5.48 \% \pm 0.51$ ) compared to the static scenario, with no difference between the minimal and spatially directed CRP scenarios. In contrast, changes in agricultural production caused the greatest shifts from the static scenario (corn trend: $-17.44 \% \pm 1.78$; small grain reinvigoration: $19.29 \% \pm 3.32$ ). Furthermore, we demonstrated varying patterns for pheasant populations among regions (Figs. 2 and 3). Independent of the agricultural policy scenario we tested, the relative abundance of pheasants in the Panhandle region remained fairly consistent, and maintained some of the best populations in Nebraska compared to other regions (Figs. 2 and 3). Similarly, the Sandhills and Central regions of Nebraska appeared resilient to agricultural policy shifts but never had large pheasant populations compared with other regions (Figs. 2 and 3). In contrast, ring-necked pheasant populations in the Southwest and Southeast regions changed drastically compared to the static scenario, particularly in response to the type of grain production favored by the policy scenario (Fig. 2). However, even though relative abundance was predicted to decline drastically in the Southwest under the corn trend scenario, it continued to maintain some of the most abundant populations of pheasants in Nebraska. In contrast, the Southeast was predicted to have abundant pheasant populations only under the most favorable agricultural policy scenario (small grain reinvigoration; Fig. 3). Regardless of the scenario, the Northeast had low relative abundance scores and each agricultural policy scenario tested predicted future reductions in pheasant populations (Figs. 2 and 3). The uneven effects of agricultural policy on pheasant habitat were apparent even within regions; various portions of Gage County responded differently to each policy scenario (Fig. 3).

\section{DISCUSSION}

Agricultural policy plays a pivotal role in influencing the abundance and distribution of wildlife populations (Ryan et al. 1998, Krebs et al. 1999), but conceptualizing the effects of policy decisions on a specific species or region is challenging. Using a SDM, we qualitatively and quantitatively estimated the predicted effects of several large-scale agricultural policy decisions on pheasant populations in Nebraska. Our findings are not surprising (e.g., loss of CRP is bad for pheasants), but by using a spatially explicit model, we are able to display where the 


\section{Nebraska \\ Gage County}
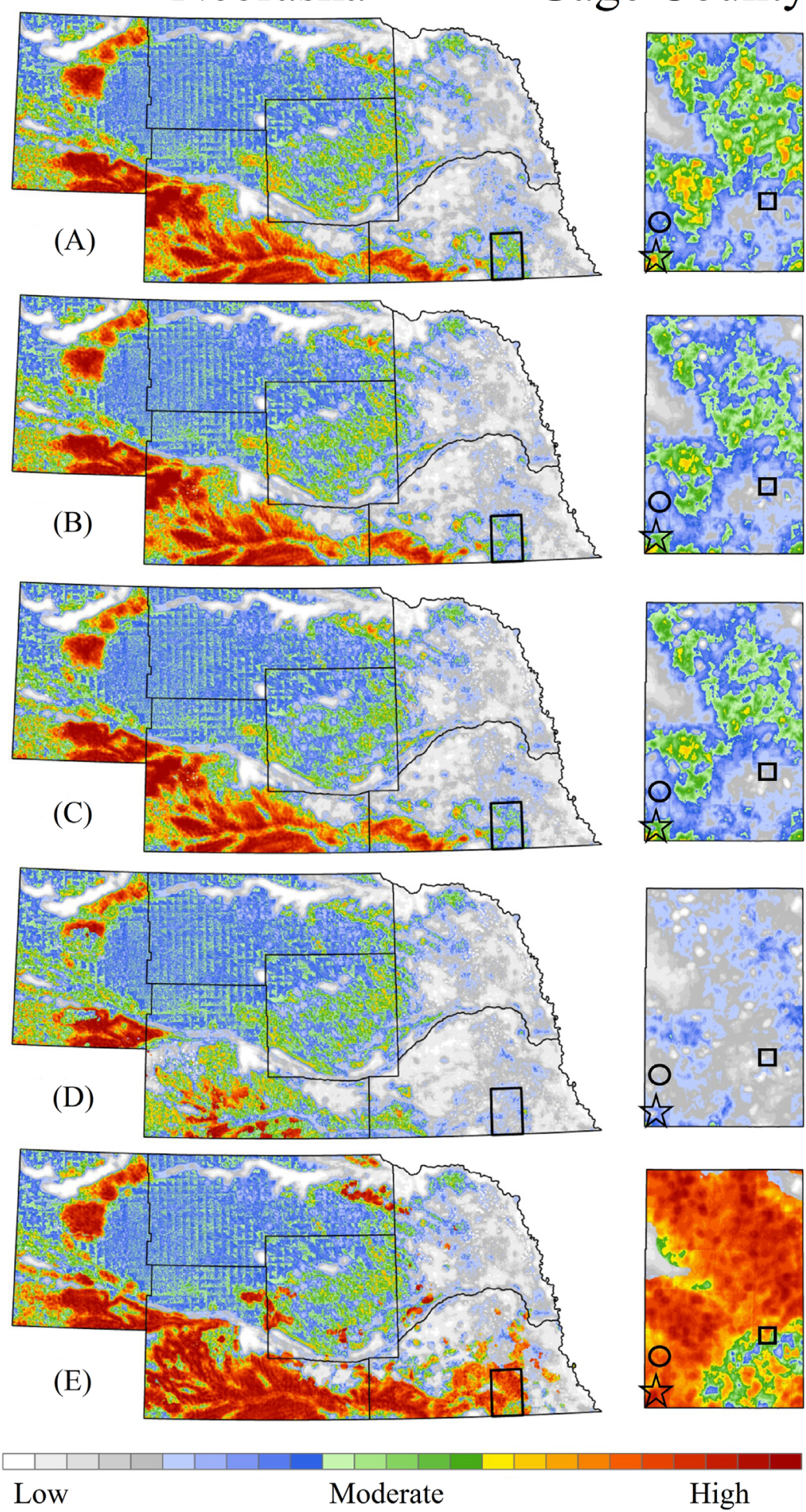

High

Figure 3. The predicted $30 \times 30-\mathrm{m}$ resolution ring-necked pheasant species distributions for 2025 based on 5 alternative agricultural policy scenarios $(\mathrm{A}=$ static, $\mathrm{B}=$ minimal Conservation Reserve Program $[\mathrm{CRP}], \mathrm{C}=$ spatially directed $\mathrm{CRP}, \mathrm{D}=$ corn trend, and $\mathrm{E}=$ small grain reinvigoration $)$ in Nebraska, USA. We categorized predicted relative abundance using a quantile approach to bin predictions from the static scenario (A) into 25 equal-area intervals ranging from low (white) to high (red) abundance. We held the range of values in each interval constant across the remaining agricultural policy scenarios (B-E) to compare relative abundance among management regions and alternative policy scenarios. Large polygons on the state map represent historical pheasant management units. The small rectangle in the southeast region is Gage County, which is enlarged and wildlife management areas within the county are defined by individual symbols ( $\vec{\xi}=$ Diamond Lake, $\circ=$ Arrowhead, and $\square=$ Rockford Lake). 
effects of policy decisions were likely to manifest in a manner that was straightforward to evaluate. Moreover, because we based our predictions on modeled species-habitat relationships rather than species populations per se, we were able to evaluate a number of alternative policy decisions that affect pheasant habitat, affording policy makers the opportunity to quickly assess and weigh diverse options.

Policy makers can glean several pieces of information by comparing SDMs from various policy scenarios. Obviously it is important to compare the outcome of each scenario on the species of interest. In our case, it is not surprising that increasing corn production would negatively affect ringnecked pheasant populations in Nebraska, but not all outcomes were as predictable (Fletcher et al. 2010). Despite previous research supporting our a priori assertion that directing CRP allotments into areas with a more favorable surrounding landscape (spatially directed CRP scenario) would have the greatest benefit to ring-necked pheasants (Nielson et al. 2008, Jorgensen et al. 2014), we found no benefit at the state scale over the minimal CRP scenario where CRP was placed haphazardly. In some regions of Nebraska, directing CRP placement performed worse than haphazard placement. Such a finding has value because imposing a policy only to see it fail has little management value and may even undermine the credibility of agencies supporting the policy decision. Given the challenges facing wildlife conservation, having a tool that illustrates a possible outcome of a policy change can help avoid pitfalls, or alternatively facilitate improvements that policy makers can further test. For example, that we failed to find a benefit to directing CRP placement may indicate that previous research was mistaken (e.g., Nielson et al. 2008, Jorgensen et al. 2014), or that our approach was misguided. The spatially directed CRP scenario placed CRP next to small grains and grasslands with the expectation of increasing pheasant abundance (Jorgensen et al. 2014). However, because we weighted the scenario at the state scale, CRP was largely placed in parts of the state where grassland habitat was not limiting. If we altered the scenario to direct CRP first to regions where grasslands are limited and then placed CRP strategically in the landscape, the outcome might differ. Although we did not test such an alternative, the capacity to test improvements to policy scenarios quickly, and prior to their implementation, is a clear benefit of SDMs.

Based on our scenarios, pheasant populations in some regions are highly resilient to changes in policy, whereas other regions are more dynamic. For example, across all scenarios, the relative abundance of pheasants remains relatively high in the Panhandle, but the Northeast had scores that remained low even under the best-case scenario (small grain reinvigoration). Neither outcome is surprising because climate constrains the efficacy of agricultural policy. In the Panhandle, access to water limits available agricultural practices, but in the Northeast abundant rainfall favors a landscape dominated by corn production. Such observations underscore the likely importance of future climate on forecasts of species distributions. Although we assumed a constant climate, shifts in climate have consequences for future land use and the resulting land cover, which may in turn affect species-habitat relationships (Guisan and Thuiller 2005). Similar to our methods, policy makers and managers could incorporate climate in predictive species distribution models and subsequently, consider multiple future climate scenarios (Thomas et al. 2004, Catano et al. 2015).

Though it is increasingly apparent that policy decisions well beyond the scope of influence of managers may constrain management success (Jorgensen et al. 2014), by using SDMs to explore different scenarios managers can identify where, and under what circumstances success is most likely. For example, the Panhandle maintains relatively high ringnecked pheasant abundance across a host of alternative scenarios, which suggests there may be a long-term benefit to investing in local habitat improvement projects or hunting access programs in the region no matter what the future brings. By contrast, managers may want to question the value of managing for ring-necked pheasants in the Northeast where the landscape is, and may likely continue to be, unconducive to supporting an abundant pheasant population. Managers have the difficult task of providing as many opportunities to enjoy and use wildlife as possible, and ultimately the choice to manage habitat for a hunted species such as ring-necked pheasant is driven by a multitude of factors (e.g., proximity to population centers). For nongame or at-risk species there can be additional considerations (e.g., federal trust status). By testing scenarios with SDMs, managers can better understand the likelihood of the population of interest to respond to management actions given a policy decision. Such a priori knowledge can facilitate proactive management that can account for the likelihood that the population will not respond, rather than a reactive response to perceived management failures.

Understanding how each region is constrained by agricultural policy can help shape management across Nebraska, but managers within each region must attempt to balance the multitude of factors that drive local wildlife and constituent needs. A benefit of using SDMs is managers can scale down to identify individual properties where management success is predicted to be the greatest within a larger region (Elith and Leathwick 2009, Hannah et al. 2014, Pradervand et al. 2014). As an example, consider 3 public properties managed for hunting opportunities in Gage County in southeast Nebraska (Fig. 3). Currently, only Diamond Lake WMA is in a landscape conducive to ringnecked pheasant management (Fig. 3). More importantly, Diamond Lake WMA is the only public hunting property in the county that appears to have the capacity to sustain ringnecked pheasant populations across all scenarios. If the objective of managers is to ensure ring-necked pheasant hunting opportunities within Gage County, improving habitat on Diamond Lake WMA may have the greatest return over the long-term, whereas habitat improvements at the other sites would appear to come with greater risk of management failure.

The challenge of predicting the future may be self-evident, but there is additional uncertainty inherent to the development 
of models of species-habitat relationships (Pearson et al. 2006, Dormann et al. 2008, Beale and Lennon 2011). Aside from questions of whether occupancy or abundance predicts habitat quality (Van Horne 1983, Mosser et al. 2009, Beerens et al. 2015), there is uncertainty that results from a lack of basic knowledge; deficiencies associated with sampling design, model development, and model selection; and of course inappropriate judgments and assumptions about systems (Mahmoud et al. 2009). In the scenarios presented here, we made specific assumptions about the future of agriculture in Nebraska. Our assumptions ultimately define the projected distribution of ring-necked pheasants in the state. Some assumptions differed between scenarios (e.g., the importance of different agricultural commodities in the future) allowing for comparisons. Other assumptions were consistent but no less important in shaping the final model outcome. In our projections of future land cover, for example, we assumed that the surrounding land cover affected the likelihood that a parcel would change land use. Surrounding land-use practices are widely used to determine the economic value of a given parcel (e.g., cash rental rates), but unique landscape features, geopolitical boundaries, surrounding infrastructure, and even social norms ultimately all play a role in determining how a particular piece of property is managed. Errors in predicting changes in land cover for a particular parcel likely have little effect on the reliability of projected pheasant populations at the scale of a management region but may alter predictions for a specific wildlife management area or certain small-scale landscape features (e.g., irrigated river valleys). Assumptions about the future importance of commodities or climatic conditions also affect the outcomes we modeled. Because even reasonable assumptions about the future may be false, managers and policy makers should recognize how such assumptions shape the validity of scenario projections.

Improvements in design or new statistical approaches can mitigate some sources of error, but it is important to realize that uncertainty is an inherent property of wildlife management. Fear of uncertainty can lead to management paralysis (Allen et al. 2011, Fontaine 2011), but managers who are willing to embrace uncertainty can still achieve desired management outcomes. Adaptive management is a mechanistic solution to resource management that allows managers to embrace uncertainty (Walters 1986, Pahl-Wostl 2007, Allen et al. 2011, Fontaine 2011). As models capable of translating policy and management actions into working hypotheses, SDMs are an ideal tool to work within an adaptive management framework (Schwartz 2012). Through active monitoring, managers can compare model projections to realized population outcomes to identify the most likely future population responses and sources of uncertainty that remain unresolved (Nichols et al. 2007).

\section{MANAGEMENT IMPLICATIONS}

As landscapes continue to change and pressures on wildlife populations continue to rise, effective management requires an understanding of how policy decisions shape management outcomes. Using SDMs to account for species-habitat relationships across ecological scales may enable managers to make predictions about how alternative policy decisions are likely to affect habitat for species across entire states, in particular regions of a state, and even at specific public properties. As support for wildlife management becomes increasingly limited because of budgetary constraints, it behooves policy makers and managers to consider the potential outcomes of policy decisions and management actions prior to acting, enabling proactive rather than reactive decision-making.

\section{ACKNOWLEDGMENTS}

Funding for this project was received from Federal Aid in Wildlife Restoration project W-89-R, and W-98-R, administered by the Nebraska Game and Parks Commission. We thank S. Taylor, T. Edwards, L. Powell, associate editor J. Gervais, and 2 anonymous reviewers for their perspective and insight. Any use of trade, firm, or product names is for descriptive purposes only and does not imply endorsement by the U.S. Government. The Nebraska Cooperative Fish and Wildlife Research Unit is supported by a cooperative agreement among the U.S. Geological Survey, the Nebraska Game and Parks Commission, the University of Nebraska, the U.S. Fish and Wildlife Service, and the Wildlife Management Institute.

\section{LITERATURE CITED}

Allen, C. R., J. J. Fontaine, K. L. Pope, and A. S. Garmestani. 2011. Adaptive management for a turbulent future. Journal of Environmental Management 92:1339-1345.

Anderson, R. P., A. T. Peterson, and M. Gómez-Laverde. 2002. Using niche-based GIS modeling to test geographic predictions of competitive exclusion and competitive release in South American pocket mice. Oikos 98:3-16.

Austin, M. 2007. Species distribution models and ecological theory: a critical assessment and some possible new approaches. Ecological Modelling 200:1-19.

Beale, C. M., and J. J. Lennon. 2011. Incorporating uncertainty in predictive species distribution modelling. Philosophical Transactions of the Royal Society B 367:247-258.

Beck, M. B., J. Chen, and O. Osidele. 2002. Random search and the reachability of target futures. Pages 207-226 in M. B. Beck, editor. Environmental foresight and models: a manifesto. Elsevier Science, Oxford, United Kingdom.

Beerens, J. M., P. C. Frederick, E. G. Noonburg, and D. E. Gawlik. 2015. Determining habitat quality for species that demonstrate dynamic habitat selection. Ecology and Evolution 5:5685-5697.

Bell, K. P., K. J. Boyle, and J. Rubin, editors. 2006. Economics of rural landuse change. Ashgate Publishing, Burlington, Vermont, USA.

Best, L. B., K. E. Freemark, J. J. Dinsmore, and M. Camp. 1995. A review and synthesis of habitat use by breeding birds in agricultural landscapes of Iowa. American Midland Naturalist 34:1-29.

Bishop, A., A. Barenberg, N. Volpe, and R. Grosse. 2011. Nebraska Land Cover Development. Rainwater Basin Joint Venture Report, Grand Island, Nebraska, USA.

Buskirk, J. V., and Y. Willi. 2004. Enhancement of farmland biodiversity with set-aside land. Conservation Biology 18:987-994.

Catano, C. P., S. S. Romañach, J. M. Beerens, L. Brandt, K. M. Hart, F. J. Mazzotti, L. Pearlstine, and J. C. Trexler. 2015. Using scenario planning to evaluate the impacts of climate change on wildlife populations and communities in the Florida Everglades. Journal of Environmental Management 55:807-823.

Chen, I. C., J. K. Hill, R. Ohlemüller, D. B. Roy, and C. D. Thomas. 2011. Rapid range shifts of species associated with high levels of climate warming. Science 333:1024-1026. 
Cumming, G. S., C. R. Allen, N. C. Ban, D. Biggs, H. C. Biggs, D. H. Cumming, A. De Vos, G. Epstein, M. Etienne, K. Maciejewski, and R. Mathevet. 2015. Understanding protected area resilience: a multi-scale, social-ecological approach. Ecological Applications 25:299-319.

Cunningham, M. A., and D. H. Johnson. 2006. Proximate and landscape factors influencing grassland bird distributions. Ecological Applications 16:1062-1075.

Dahlgren, R. B. 1988. Distribution and abundance of the ring-necked pheasant in North America. Pages 29-43 in D. L. Hallett, W. R. Edwards, and G. V. Burger, editors. Pheasants: symptoms of wildlife problems on agricultural lands. North Central Section of The Wildlife Society, Bloomington, Indiana, USA.

Dormann, C. F., O. Purschke, J. R. G. Márquez, S. Lautenbach, and B. Schröder. 2008. Components of uncertainty in species distribution analysis: a case study of the great grey shrike. Ecology 89:3371-3386.

Elith, J., and J. R. Leathwick. 2009. Species distribution models: ecological explanation and prediction across space and time. Annual Review of Ecology, Evolution, and Systematics 40:677-697.

Fargione, J. E., R. J. Plevin, and J. D. Hill. 2010. The ecological impact of biofuels. Annual Review of Ecology, Evolution, and Systematics 41:351-377.

Fisher, J. R., and S. K. Davis. 2010. From Wiens to Robel: a review of grassland-bird habitat selection. Journal of Wildlife Management 74:265-273.

Fletcher, R. J., Jr., and R. R. Koford. 2002. Habitat and landscape associations of breeding birds in native and restored grasslands. Journal of Wildlife Management 66:1011-1022.

Fletcher, R. J., Jr., B. A. Robertson, J. Evans, P. J. Doran, J. R. Alavalapati, and D. W. Schemske. 2010. Biodiversity conservation in the era of biofuels: risks and opportunities. Frontiers in Ecology and the Environment 9:161-168.

Fontaine, J. J. 2011. Improving our legacy: incorporation of adaptive management into state wildlife action plans. Journal of Environmental Management 92:1403-1408.

Franklin, J. 2010. Moving beyond static species distribution models in support of conservation biogeography. Diversity and Distributions 16:321-330.

Gelman, A., J. B. Carlin, H. S. Stern, and D. B. Rubin. 2004. Bayesian data analysis. Chapman \& Hall/CRC, New York, New York, USA.

Gelman, A., and J. Hill. 2007. Data analysis using regression and multilevel/ hierarchical models. Cambridge University Press, Cambridge, United Kingdom.

Giudice, J. H., and K. J. Haroldson. 2007. Using regional wildlife surveys to assess the CRP: scale and data quality issues. Journal of Field Ornithology 78:140-151.

Giudice, J. H., and J. T. Ratti. 2001. Ring-necked pheasant (Phasianus colchicus). No. 572 in A. Poole and F. Gill, editors. The birds of North America. The Birds of North America, Inc., Philadelphia, Pennsylvania, USA.

Gottschalk, T. K., T. Diekötter, K. Ekschmitt, B. Weinmann, F. Kuhlmann, T. Purtauf, J. Dauber, and V. Wolters. 2007. Impact of agricultural subsidies on biodiversity at the landscape level. Landscape Ecology 22:643-656.

Groves, C. R. 2003. Drafting a conservation blueprint: a practitioner's guide to planning for biodiversity. Island Press, Washington, D.C., USA.

Guisan, A., C. H. Graham, J. Elith, and F. Huettmann. 2007. Sensitivity of predictive species distribution models to change in grain size. Diversity and Distributions 13:332-340.

Guisan, A., and W. Thuiller. 2005. Predicting species distribution: offering more than simple habitat models. Ecology Letters 8:993-1009.

Guisan, A., R. Tingley, J. B. Baumgartner, I. Naujokaitis-Lewis, P. R. Sutcliffe, A. I. Tulloch, T. J. Regan, L. Brotons, E. McDonaldMadden, C. Mantyka-Pringle, and T. G. Martin. 2013. Predicting species distributions for conservation decisions. Ecology Letters 16:1424-1435.

Guisan, A., and N. E. Zimmermann. 2000. Predictive habitat distribution models in ecology. Ecological Modelling 135:147-186.

Halpern, B. S., C. R. Pyke, H. E. Fox, J. C. Haney, M. A. Schlaepfer, and P. Zaradic. 2006. Gaps and mismatches between global conservation priorities and spending. Conservation Biology 20:56-64.

Hannah, L., L. Flint, A. D. Syphard, M. A. Moritz, L. B. Buckley, and I. M. McCullough. 2014. Fine-grain modeling of species' response to climate change: holdouts, stepping-stones, and microrefugia. Trends in Ecology and Evolution 29:390-397.

Hansen, L., P. Feather, and D. Shank. 1999. Valuation of agriculture's multi-site environmental impacts: an application to pheasant hunting. Agricultural and Resource Economics Review 28:199-207.

Helzer, C. J., and D. E. Jelinski. 1999. The relative importance of patch area and perimeter-area ratio to grassland breeding birds. Ecological Applications 9:1448-1458.

Herkert, J. R. 2009. Response of bird populations to farmland set-aside programs. Conservation Biology 23:1036-1040.

Hiller, T. L., L. A. Powell, T. D. McCoy, and J. J. Lusk. 2009. Long-term agricultural land-use trends in Nebraska, 1866-2007. Great Plains Research 19:225-237.

Jorgensen, C. J., A. A. Bishop, J. J. Lusk, L. A. Powell, and J. J. Fontaine. 2014. Assessing landscape constraints on species abundance: does the neighborhood limit species response to local habitat conservation programs? PLoS ONE 9:e99339.

Krebs, J. R., J. D. Wilson, R. B. Bradbury, and G. M. Siriwardena. 1999. The second silent spring? Nature 400:611-612.

Leif, A. P. 1994. Survival and reproduction of wild and pen-reared ringnecked pheasant hens. Journal of Wildlife Management 58:501-506.

Luoto, M., R. Virkkala, and R. K. Heikkinen. 2007. The role of land cover in bioclimatic models depends on spatial resolution. Global Ecology and Biogeography 16:34-42.

Mahmoud, M., Y. Liu, H. Hartmann, S. Stewart, T. Wagener, D. Semmens, R. Stewart, H. Gupta, D. Dominguez, F. Dominguez, and D. Hulse. 2009. A formal framework for scenario development in support of environmental decision-making. Environmental Modelling and Software 24:798-808

Margules, C. R., and R. L. Pressey. 2000. Systematic conservation planning. Nature 405:243-253.

Mattison, E. H., and K. Norris. 2005. Bridging the gaps between agricultural policy, land-use and biodiversity. Trends in Ecology and Evolution 20:610-616.

McCoy, T. D., M. R. Ryan, E. W. Kurzejeski, and L. W. Burger, Jr. 1999. Conservation Reserve Program: source or sink habitat for grassland birds in Missouri? Journal of Wildlife Management 63:530-538.

Merow, C., M. J. Smith, T. C. Edwards, A. Guisan, S. M. McMahon, S. Normand, W. Thuiller, R. O. Wüest, N. E. Zimmermann, and J. Elith. 2014. What do we gain from simplicity versus complexity in species distribution models? Ecography 37:1267-1281.

Mosser, A., J. M. Fryxell, L. Eberly, and C. Packer. 2009. Serengeti real estate: density vs. fitness-based indicators of lion habitat quality. Ecology Letters 12:1050-1060.

Nassauer, J., and R. C. Corry. 2004. Using normative scenarios in landscape ecology. Landscape Ecology 19:343-356.

Nichols, J. D., M. C. Runge, F. A. Johnson, and B. K. Williams. 2007. Adaptive harvest management of North American waterfowl populations: a brief history and future prospects. Journal of Ornithology 148:343-349.

Nielsen, S. E., C. J. Johnson, D. C. Heard, and M. S. Boyce. 2005. Can models of presence-absence be used to scale abundance? Two case studies considering extremes in life history. Ecography 28:197-208.

Nielson, R. M., L. L. McDonald, J. P. Sullivan, C. Burgess, D. S. Johnson, D. H. Johnson, S. Bucholtz, S. Hyberg, and S. Howlin. 2008. Estimating the response of ring-necked pheasants (Phasianus colchicus) to the Conservation Reserve Program. Auk 125:434-444.

Pahl-Wostl, C. 2007. Transitions towards adaptive management of water facing climate and global change. Water Resources Management 21:49-62.

Patterson, M. P., and L. B. Best. 1996. Bird abundance and nesting success in Iowa CRP fields: the importance of vegetation structure and composition. American Midland Naturalist 135:153-167.

Pearson, R. G., W. Thuiller, M. B. Araújo, E. Martinez-Meyer, L. Brotons, C. McClean, L. Miles, P. Segurado, T. P. Dawson, and D. C. Lees. 2006. Model-based uncertainty in species range prediction. Journal of Biogeography 33:1704-1711.

Peterson, G. D., G. S. Cumming, and S. R. Carpenter. 2003. Scenario planning: a tool for conservation in an uncertain world. Conservation Biology 17:358-366.

Polyakov, M., and D. Zhang. 2008. Property tax policy and land-use change. Land Economics 84:396-408.

Pradervand, J. N., A. Dubuis, L. Pellissier, A. Guisan, and C. Randin. 2014. Very high resolution environmental predictors in species distribution 
models: moving beyond topography? Progress in Physical Geography 38:79-96.

Rahmig, C. J., W. E. Jensen, and K. A. With. 2008. Grassland bird responses to land management in the largest remaining tallgrass prairie. Conservation Biology 23:420-432

Rashford, B. S., J. A. Walker, and C. T. Bastian. 2011. Economics of grassland conversion to cropland in the Prairie Pothole Region. Conservation Biology 25:276-284.

Robertson, B. A., R. A. Rice, T. S. Sillett, C. A. Ribic, B. A. Babcock, D. A. Landis, J. R. Herkert, R. J. Fletcher, Jr., J. J. Fontaine, P. J. Doran, and D. W. Schemske. 2012. Are agrofuels a conservation threat or opportunity for grassland birds in the United States? Condor 114:679-688.

Robertson, P. A. 1996. Does nesting cover limit abundance of ring-necked pheasant in North America? Wildlife Society Bulletin 24:98-106.

Rodgers, R. D. 1999. Why haven't pheasant populations in western Kansas increased with CRP? Wildlife Society Bulletin 27:654-665.

Rooney, W. L., J. Blumenthal, B. Bean, and J. E. Mullet. 2007. Designing sorghum as a dedicated bioenergy feedstock. Biofuels, Bioproducts and Biorefining 1:147-157.

Rosenzweig, M. L. 1991. Habitat selection and population interactions: the search for mechanism. American Naturalist 137:S5-S28.

Ryan, M. R., L. W. Burger, and E. W. Kurzejeski. 1998. The impact of CRP on avian wildlife: a review. Journal of Production Agriculture 11:61-66.

Schwartz, M. W. 2012. Using niche models with climate projections to inform conservation management decisions. Biological Conservation 155:149-156.

Schwartz, P. 1991. The art of the long view. Doubleday, New York, New York, USA.

Secchi, S., P. W. Gassman, J. R. Williams, and B. A. Babcock. 2009. Cornbased ethanol production and environmental quality: a case of Iowa and the conservation reserve program. Journal of Environmental Management 44:732-744.

Shirley, S. M., Z. Yang, R. A. Hutchinson, J. D. Alexander, K. McGarigal, and M. G. Betts. 2013. Species distribution modelling for the people: unclassified Landsat imagery predicts bird occurrence at fine resolutions. Diversity and Distributions 19:855-866.

Shulski, M. D., N. A. Umphlett, T. B. Pathak, and K. G. Hubbard. 2013. Climate change: what does it mean for Nebraska? University of Nebraska, Institute of Agriculture and Natural Resources NebGuide G2208, Lincoln, USA.

Simonsen, V. L., and J. J. Fontaine. 2016. Landscape context influences nest survival in a Midwest grassland. Journal of Wildlife Management 80:877-883.

Smith, S. J., J. Edmonds, C. A. Hartin, A. Mundra, and K. Calvin. 2015. Near-term acceleration in the rate of temperature change. Nature Climate Change 5:333-336.

Stubbs, M. 2014. Conservation Reserve Program (CRP): status and issues. Congressional Research Service Report 42783, Washington, D.C., USA.

Sullivan, P., D. Hellerstein, L. Hansen, R. Johansson, S. Koenig, R. N. Lubowski, W. D. McBride, D. A. McGranaha, M. J. Roberts, S. J. Vogel, and S. Bucholz. 2004. The Conservation Reserve Program: economic implications for rural America. USDA-ERS Agricultural Economic Report 834, Washington, D.C., USA.
Szilagyi, J. 1999. Streamflow depletion investigations in the Republican River basin: Colorado, Nebraska, and Kansas. Journal of Environmental Systems 27:251-263.

Taylor, M. W., C. W. Wolfe, and W. L. Baxter. 1978. Land-use change and ring-necked pheasants in Nebraska. Wildlife Society Bulletin 4:226-230.

Thomas, C. D., A. Cameron, R. E. Green, M. Bakkenes, L. J. Beaumont, Y. C. Collingham, B. F. Erasmus, M. F. De Siqueira, A. Grainger, L. Hannah, and L. Hughes. 2004. Extinction risk from climate change. Nature 427:145-148.

Tilman, D., J. Fargione, B. Wolff, C. D’Antonio, A. Dobson, R. Howarth, D. Schindler, W. H. Schlesinger, D. Simberloff, and D. Swackhamer. 2001. Forecasting agriculturally driven global environmental change. Science 292:281-284.

U.S. Department of Agriculture [USDA]. 2013. Conservation Reserve Program Sign-Up 45 Environmental Benefits Index. <http://www.fsa. usda.gov/Internet/FSA_File/su45ebifactsheet.pdf $>$. Accessed 1 Mar 2014.

U.S. Department of Agriculture [USDA]. 2014. Economic, statistics, and market information system. $<$ http://usda.mannlib.cornell.edu/MannUsda/ homepage.do $>$. Accessed 1 Mar 2014.

U.S. Energy Independence and Security Act. 2007. H.R. 6-110th Congress: Energy Independence and Security Act of 2007. <https://www. govtrack.us/congress/bills/110/hr6 > Accessed 1 Apr 2017.

Van Horne, B. 1983. Density as a misleading indicator of habitat quality. Journal of Wildlife Management 47:893-901.

Walters, C. J. 1986. Adaptive management of renewable resources. McMillan, New York, New York, USA.

Walthall, C. L., J. Hatfield, P. Backlund, L. Lengnick, E. Marshall, M. Walsh, S. Adkins, M. Aillery, E. A. Ainsworth, C. Ammann, C. J. Anderson, I. Bartomeus, L. H. Baumgard, F. Booker, B. Bradley, D. M. Blumenthal, J. Bunce, K. Burkey, S. M. Dabney, J. A. Delgado, J. Dukes, A. Funk, K. Garrett, M. Glenn, D. A. Grantz, D. Goodrich, S. Hu, R. C. Izaurralde, R. A. C. Jones, S. H. Kim, A. D. B. Leaky, K. Lewers, T. L. Mader, A. McClung, J. Morgan, D. J. Muth, M. Nearing, D. M. Oosterhuis, D. Ort, C. Parmesan, W. T. Pettigrew, W. Polley, R. Rader, C. Rice, M. Rivington, E. Rosskopf, W. A. Salas, L. E. Sollenberger, R. Srygley, C. Stöckle, E. S. Takle, D. Timlin, J. W. White, R. Winfree, L. Wright-Morton, and L. H. Ziska. 2012. Climate change and agriculture in the United States: effects and adaptation. USDA Technical Bulletin 1935, Washington, D.C., USA.

Wetherald, R. T., and S. Manabe. 1995. The mechanisms of summer dryness induced by greenhouse warming. Journal of Climate 8:3096-3108.

Wiens, J. A. 1973. Interterritorial habitat variation in grasshopper and savannah sparrows. Ecology 54:877-884.

Wilhelmi, O. V., and D. A. Wilhite. 2002. Assessing vulnerability to agricultural drought: a Nebraska case study. Natural Hazards 25:37-58.

$\mathrm{Wu}, \mathrm{J} .1999$. Crop insurance, acreage decisions, and nonpoint-source pollution. American Journal of Agricultural Economics 81:305-320.

Associate Editor: Gervais. 